\title{
Ventricular anti-arrhythmic effects of heptanol in hypokalaemic, Langendorff-perfused mouse hearts
}

\author{
GARY TSE $^{1}$, VIVIAN TSE ${ }^{2}$ and JIE MING YEO ${ }^{3}$ \\ ${ }^{1}$ School of Biomedical Sciences, Li Ka Shing Faculty of Medicine, University of Hong Kong, \\ Hong Kong, SAR, P.R. China; ${ }^{2}$ Department of Physiology, McGill University, Montreal, Quebec H3G 1YG, Canada; \\ ${ }^{3}$ School of Medicine, Imperial College London, SW7 2AZ London, UK
}

Received November 17, 2015; Accepted December 11, 2015

DOI: 10.3892/br.2016.577

\begin{abstract}
Ventricular arrhythmic and electrophysiological properties were examined during normokalaemia (5.2 $\left.\mathrm{mM}\left[\mathrm{K}^{+}\right]\right)$, hypokalaemia $\left(3 \mathrm{mM}\left[\mathrm{K}^{+}\right]\right)$or hypokalaemia in the presence of 0.1 or $2 \mathrm{mM}$ heptanol in Langendorff-perfused mouse hearts. Left ventricular epicardial or endocardial monophasic action potential recordings were obtained during right ventricular pacing. Hypokalaemia induced ventricular premature beats (VPBs) in 5 of 7 and ventricular tachycardia $(\mathrm{VT})$ in 6 of 7 hearts $(\mathrm{P}<0.01)$, prolonged action potential durations $\left(\mathrm{APD}_{90}\right)$ from $36.2 \pm 1.7$ to $55.7 \pm 2.0 \mathrm{msec}$ $(\mathrm{P}<0.01)$ and shortened ventricular effective refractory periods (VERPs) from $44.5 \pm 4.0$ to $28.9 \pm 3.8 \mathrm{msec}(\mathrm{P}<0.01)$ without altering conduction velocities $(\mathrm{CVs})(0.17 \pm 0.01 \mathrm{~m} / \mathrm{sec}$, $\mathrm{P}>0.05)$, reducing excitation wavelengths $(\lambda, \mathrm{CV} \times \mathrm{VERP})$ from $7.9 \pm 1.1$ to $5.1 \pm 0.3 \mathrm{~mm}(\mathrm{P}<0.05)$ while increasing critical intervals (CI, $\mathrm{APD}_{90}$-VERP) from $-8.3 \pm 4.3$ to $26.9 \pm 2.0 \mathrm{msec}$ $(\mathrm{P}>0.001)$. Heptanol $(0.1 \mathrm{mM})$ prevented VT, restored effective refractory period (ERP) to $45.2 \pm 2.9 \mathrm{msec}$ without altering $\mathrm{CV}$ or $\mathrm{APD}$, returning $\lambda$ to control values $(\mathrm{P}>0.05)$ and $\mathrm{CI}$ to $8.4 \pm 3.8 \mathrm{msec}(\mathrm{P}<0.05)$. Heptanol $(2 \mathrm{mM})$ prevented VPBs and VT, increased ERP to 67.7 $\pm 7.6 \mathrm{msec}(\mathrm{P}<0.05)$, and reduced $\mathrm{CV}$ to $0.11 \pm 0.1 \mathrm{~m} / \mathrm{sec}(\mathrm{P}<0.001)$ without altering APD $(\mathrm{P}>0.05)$, returning $\lambda$ and $C I$ to control values $(\mathrm{P}>0.05)$. Anti-arrhythmic effects of heptanol during hypokalaemia were explicable by ERP changes, scaling $\lambda$ and CI.
\end{abstract}

\section{Introduction}

Cardiac excitation involves an orderly sequence of action potential activation and recovery, and subsequently, its conduction through successive myocardial regions via

Correspondence to: Dr Gary Tse, School of Biomedical Sciences, Li Ka Shing Faculty of Medicine, University of Hong Kong, 3/F Laboratory Block, 22 Sassoon Road, Hong Kong, SAR, P.R. China E-mail: gary.tse@doctors.org.uk

Key words: heptanol, mouse, ventricular arrhythmia, hypokalaemia, gap junction, sodium channel gap junctions (1-3). Disruption of these processes, through alterations in conduction velocity (CV), effective refractory period (ERP) or action potential duration (APD), can result in ventricular arrhythmias. This can be exemplified by hypokalaemia, a commonly encountered condition in clinical practice and an acquired cause of long QT syndrome (4). Prolongations in the electrocardiographic QT interval reflect increases in APDs, in turn predisposing to a particular form of ventricular tachycardia known as torsades de pointes (5).

A strategy used to prevent such adverse rhythms is to increase the ERP. This can be achieved using drugs that act on various cardiac ion channels in the cell membrane. However, certain anti-arrhythmic agents can have the undesired and paradoxical effects of themselves inducing arrhythmias (6) through mechanisms such as APD prolongation (7) or CV slowing (8). Therefore, there is a requirement to develop novel drugs with improved safety profiles (9). One potential method is to target intercellular communication, which is mediated by gap junctions. For example, gap junction openers such as rotigaptide (10), and inhibitors such as carbenaloxone (11), have demonstrated promising results of preventing ventricular arrhythmias induced by ischaemia in dogs.

Mouse hearts have been extensively used to model arrhythmogenesis due to their amenability for pharmacological and genetic manipulation (12). In particular, the Langendorff perfusion system has the benefit of containing all myocardial cell types with intact intercellular coupling (13). Hypokalaemia has previously been shown to elicit frequent early after-depolarisation phenomena and sustained ventricular tachy-arrhythmias, with prolonged APDs and reduced ERPs implicated as the underlying re-entrant substrates $(14,15)$. Heptanol is a specific gap junction inhibitor when $<1 \mathrm{mM}(16,17)$, but also blocks sodium channels at $\geq 2 \mathrm{mM}(16,18)$. Previous experiments have demonstrated ventricular tachy-arrhythmias occurring at $2 \mathrm{mM}$ heptanol, which was previously attributed to its effect on slowing CV despite simultaneously increasing ERP and leaving APD unaltered (19). At $0.1 \mathrm{mM}$, it had no pro-arrhythmic effects, increased ERP without altering CV or APD. The present study hypothesised that combining hypokalaemia and heptanol may paradoxically prevent ventricular arrhythmogenesis. This may be explained through heptanol reversing the ERP changes produced by hypokalaemia. However, VPBs and ventricular tachycardia (VT) as well as 
the electrophysiological parameters observed during hypokalaemia may be affected differently at 0.1 and $2 \mathrm{mM}$ heptanol due to their differing ion channel specificities.

The present experiments first confirmed previous observations of VPBs and VT during hypokalaemic conditions. Heptanol at $0.1 \mathrm{mM}$ prevented VT whilst returning ERPs to normokalaemic values without affecting APDs or CVs. By contrast, at $2 \mathrm{mM}$, it prevented VPBs and VT, associated with increased ERPs, despite reduced CVs and no further changes to APDs. The present results suggest that the net effect of a pharmacological agent on arrhythmogenicity is dependent upon the association between ERP, CV and APD, and that changes in a single parameter are sufficient to influence the arrhythmic outcome. It appears that wavelength shortening consistently predicted the occurrence of VT, implying that re-entry may be an underlying mechanism. Gap junction inhibitors, not just its openers, have protective effects against arrhythmias and their therapeutic effects warrant further exploration.

\section{Materials and methods}

Solutions. The experiments described in the present study used Krebs-Henseleit solution $\left(119 \mathrm{mM} \mathrm{NaCl}, 25 \mathrm{mM} \mathrm{NaHCO}_{3}, 4 \mathrm{mM}\right.$ $\mathrm{KCl}, 1.2 \mathrm{mM} \mathrm{KH}_{2} \mathrm{PO}_{4}, 1 \mathrm{mM} \mathrm{MgCl}{ }_{2}, 1.8 \mathrm{mM} \mathrm{CaCl}_{2}, 10 \mathrm{mM}$ glucose and $2 \mathrm{mM}$ sodium pyruvate) $(\mathrm{pH} 7.4)$ that had been bicarbonate-buffered and bubbled with $95 \% \mathrm{O}_{2}-5 \% \mathrm{CO}_{2}(20)$. Hypokalaemic solution was prepared by decreasing the amount of $\mathrm{KCl}$ added to produce a final $\left[\mathrm{K}^{+}\right]$of $3 \mathrm{mM}$.

Preparation of Langendorff-perfused mouse hearts. In total, 14 mice (wild-type, 129 genetic background) between 5 and 7 months of age were used in the study. These mice were maintained in an animal facility at room temperature $\left(21 \pm 1^{\circ} \mathrm{C}\right)$, subject to a $12: 12 \mathrm{~h} \mathrm{light/dark}$ cycle with free access to sterile rodent chow and water. All the experiments described here complied with the UK Animals (Scientific Procedures) Act 1986. The procedures for the preparation of Langendorff-perfused mouse hearts are as follows. Mice were sacrificed by cervical dislocation in accordance with Sections 1(c) and 2 of Schedule 1 of the UK Animals (Scientific Procedures) Act 1986. The hearts were rapidly excised and immediately submerged in ice-cold Krebs-Henseleit solution. Cannulation of the aorta was achieved using a tailor-made 21-gauge cannula that had been prefilled with ice-cold buffer. Using a micro-aneurysm clip (Harvard Apparatus, Kent, UK), the heart was securely attached to the perfusion system. Retrograde perfusion was initiated at a rate of 2-2.5 ml min using a peristaltic pump (Watson-Marlow Bredel pumps model 505S; Falmouth, Cornwall, UK) with the perfusate passing through 200 and $5 \mu \mathrm{m}$ filters successively and heated to $37^{\circ} \mathrm{C}$ using a water jacket and circulator before reaching the aorta. The hearts that regained their pink colour and spontaneous rhythmic activity were studied further ( $90 \%)$. The remaining $10 \%$ were discarded. Perfusion took place for a further $20 \mathrm{~min}$ to minimise any residual effects of catecholamine released endogenously, prior to studying the electrophysiology of the perfused hearts.

Stimulation protocols. Electrical stimulation was achieved using paired platinum electrodes ( $1 \mathrm{~mm}$ interpole distance) placed at the basal right ventricular epicardium. This occurred at $8 \mathrm{~Hz}$, using square wave pulses that were $2 \mathrm{msec}$ in duration, with a stimulation voltage set to thrice the diastolic threshold (Grass S48 stimulator; Grass-Telefactor, Slough, UK) immediately following the start of perfusion. Programmed electrical stimulation (PES) using the S1S2 protocol was used to assess arrhythmogenicity and identify re-entrant substrates. This consisted of a drive train of eight regularly paced S1 stimuli separated by a $125 \mathrm{msec}$ basic cycle length (BCL), followed by premature S2 extra-stimuli every ninth stimulus. S1S2 intervals first equalled the pacing interval and following this were successively reduced by $1 \mathrm{msec}$ with each nine stimulus cycle until arrhythmic activity was initiated or refractoriness was reached, whereupon the S2 stimulus elicited no response.

Recording procedures. Recordings of the monophasic action potentials (MAPs) from the left ventricular epicardium were obtained using a MAP electrode (Linton Instruments, Harvard Apparatus). MAPs from the left ventricular endocardium were obtained using a custom-made MAP electrode that was made from two strands of $0.25 \mathrm{~mm}$ Teflon-coated silver wire (99.99\% purity; Advent Research Materials, Oxfordshire, UK). The tips of the electrode were galvanically-chlorided to eliminate DC offset. The endocardial electrode was introduced through a small access window made in the inter-ventricular septum and subsequently positioned on the lateral wall of the left ventricular cavity. The positions for stimulating and recording electrodes were maintained at constant positions, with a constant inter-electrode distance of $3 \mathrm{~mm}$. This allowed conduction velocities to be determined from the activation latencies. All recordings were performed using a $\mathrm{BCL}$ of $125 \mathrm{msec}(8 \mathrm{~Hz})$ to exclude rate-dependent differences in APDs. MAPs were pre-amplified using a NL100AK head stage, amplified with a NL104A amplifier and band pass filtered between $0.5 \mathrm{~Hz}$ and $1 \mathrm{kHz}$ using a NL125/6 filter (Neurolog, Hertfordshire, UK) and subsequently digitized (1401plus MKII; Cambridge Electronic Design, Cambridge, UK) at $5 \mathrm{kHz}$. The samples were analysed using Spike2 software (Cambridge Electronic Design). MAP waveforms that did not match the previous established stringent criteria for MAP signals (21) were rejected. They must have stable baselines, fast upstrokes, with no inflections or negative spikes, and a rapid first phase of repolarization. Repolarization of $0 \%$ was measured at the peak of the MAP and $100 \%$ repolarization was measured at the point of return of the potential to baseline (21-23).

The following parameters were obtained from the experimental records: i) Activation latency, defined as the time difference between the stimulus and the peak of the MAP; and ii) $\mathrm{CV}$, as the ratio of the inter-electrode distance to the activation latency. As the latter distance was kept constant, CVs were inversely proportional to the corresponding activation latencies; iii) ERP, defined as the longest S1S2 interval at which the $\mathrm{S} 2$ extrastimulus failed to initiate a ventricular signal during PES; iv) $\mathrm{APD}_{\mathrm{x}}$, the time difference between the peak of the MAP and $x=30,50,70$ and $90 \%$ repolarisation; v) $\triangle \mathrm{APD}_{\mathrm{x}}$, given by the endocardial - epicardial difference; vi) local critical intervals for re-excitation at the epicardium or endocardium, given by $\mathrm{APD}_{90}$ - ERP; vii) transmural critical interval for re-excitation of the endocardium by the 
A

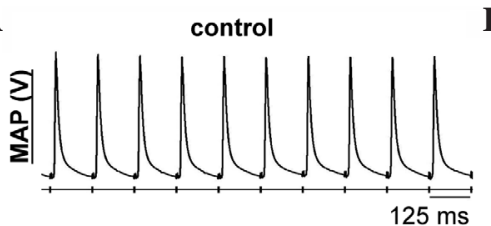

B

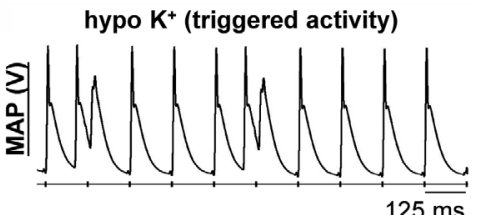

C

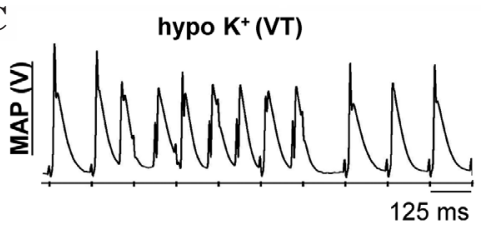

D

hypo $\mathrm{K}^{+}+0.1 \mathrm{mM}$ heptanol (triggered activity and no VT)

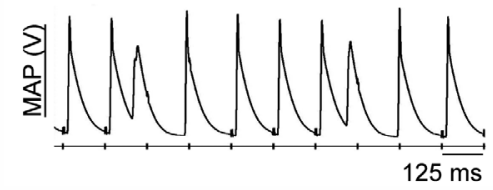

F

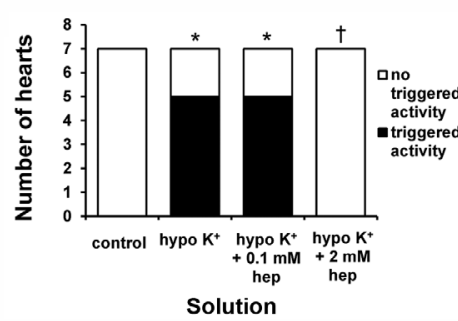

E hypo $\mathrm{K}^{+}+2 \mathrm{mM}$ heptanol (no triggered activity or VT)
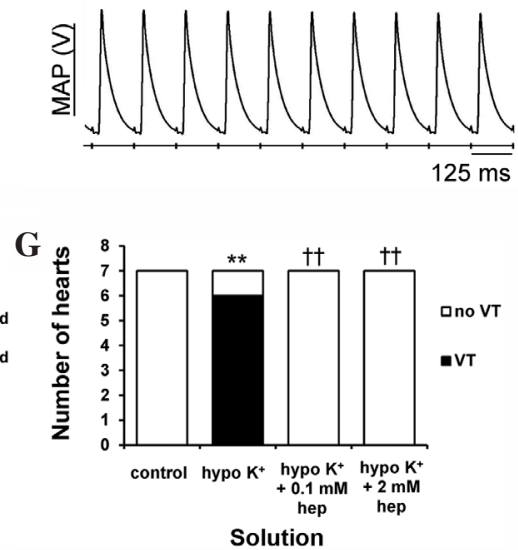

Figure 1. Representative traces of epicardial monophasic action potential (MAP) recordings obtained during regular $8 \mathrm{~Hz}$ pacing. (A) A typical regular rhythm with each MAP occurring directly after its preceding stimulus can be observed under control conditions (5.2 mM [ $\left.\left.\mathrm{K}^{+}\right]\right)$. (B) Hypokalaemia (3 mM $\left[\mathrm{K}^{+}\right]$) produced both ventricular premature beats (VPBs) and (C) ventricular tachycardia (VT). (D) Heptanol at $0.1 \mathrm{mM}$ prevented VT but did not affect VPBs, (E) whereas at $2 \mathrm{mM}$ prevented VPBs and VT during hypokalaemic conditions. (F) The proportion of hearts showing VPBs was significantly increased by hypokalaemia (Fisher's exact test, $\left.{ }^{*} \mathrm{P}<0.05\right)$. This was unaltered by heptanol at $0.1 \mathrm{mM}(\mathrm{P}>0.05)$, but subsequently decreased at $2 \mathrm{mM}\left({ }^{\mathrm{P}}<0.05\right)$. $(\mathrm{G}) \mathrm{The}$ proportion of hearts showing VT was significantly increased by hypokalaemia $\left({ }^{* *} \mathrm{P}<0.01\right)$ and subsequently decreased by 0.1 and $2 \mathrm{mM}$ heptanol $\left({ }^{\circ} \mathrm{P}<0.01\right)$.

epicardium given by (epicardial activation latency + epicardial $\mathrm{APD}_{90}$ ) - [endocardial activation latency + endocardial ventricular effective refractory periods (VERP)], and of the epicardium by the endocardium given by (endocardial activation latency + endocardial $\mathrm{APD}_{90}$ ) - (epicardial activation latency + epicardial VERP) (15); viii) excitation wavelength given by $\mathrm{CV} \times \mathrm{ERP}$; ix) $\mathrm{APD}_{90}$ restitution gradient obtained from restitution curves plotting $\mathrm{APD}_{90}$ against the previous diastolic interval (DI), assuming its maximum value at the shortest S1S2 interval studied; $x$ ) critical DI, DI $_{\text {crit }}$, defined as the $\mathrm{DI}$ at which the gradient of the $\mathrm{APD}_{90}$ restitution curve reaches unity; xi) maximum $\mathrm{APD}_{90}$ reduction, a measure of $\mathrm{APD}_{90}$ restitution heterogeneity, defined as the maximum $\mathrm{APD}_{90}$ reduction observed between the longest and shortest S1S2 intervals achieved during PES; xii) CV restitution gradient obtained from restitution curves plotting $\mathrm{CV}$ against the previous DI, assuming its maximal value at the shortest S1S2 interval studied; xiii) CV restitution curve time constant, $\tau$; xiv) maximum $\mathrm{CV}$ reduction, a measure of $\mathrm{CV}$ restitution heterogeneity, defined as the maximum $\mathrm{CV}$ reduction observed between the longest and shortest S1S2 interval achieved during PES (24).

Statistical analysis. All the values are expressed as mean \pm standard error of the mean. Different experimental groups were compared by one-way analysis of variance (ANOVA) and Student's t-test as appropriate. $\mathrm{P}<0.05$ was considered to indicate a statistically significant difference. Categorical data were compared with Fisher's exact test (one-tailed), with $\mathrm{P}<0.05$ considered to indicate a statistically significant difference.

\section{Results}

Ventricular arrhythmogenicity, action potential activation and recovery properties. Ventricular arrhythmogenicity and its association with action potential activation and recovery properties were examined under normokalaemic conditions $\left(5.2 \mathrm{mM}\left[\mathrm{K}^{+}\right]_{\mathrm{o}}\right)$, hypokalaemia alone $\left(3 \mathrm{mM}\left[\mathrm{K}^{+}\right]_{\mathrm{o}}\right)$ and hypokalaemia in the presence of 0.1 or $2 \mathrm{mM}$ heptanol in Langendorff-perfused mouse hearts. The right ventricular epicardium was electrically stimulated using either regular $8 \mathrm{~Hz}$ pacing or PES $(25,26)$. MAP recordings were obtained from the left ventricular epicardium or endocardium. The epicardial stimulating and recording electrodes were separated by a constant distance of $3 \mathrm{~mm}$, which permitted CVs to be calculated from the respective activation latencies and therefore enabled their comparisons between experiments. A VPB was defined as an action potential occurring prior to full repolarisation, and VT was defined as a succession of five or more action potentials at intervals closer than the BCL.

Concentrations of 0.1 and 2 mM heptanolexertanti-arrhythmic effects under hypokalaemic conditions. The initial experiments conducted during regular pacing demonstrated consistent ventricular activity in the absence of spontaneous arrhythmias in all of the seven hearts studied under normokalaemic conditions (Fig. 1A). By contrast, VPBs (Fig. 1B) occurred in 5 hearts (Fisher's exact test, $\mathrm{P}<0.05$ ) and VT (Fig. 1C) in 6 hearts $(\mathrm{P}<0.01)$ during hypokalaemia, as summarised in Fig. 1F and G, respectively. To test the effects of heptanol, it was first applied at $0.1 \mathrm{mM}$ under hypokalaemic conditions and was found to prevent VT in 6 hearts $(\mathrm{P}<0.01)$ without 
A

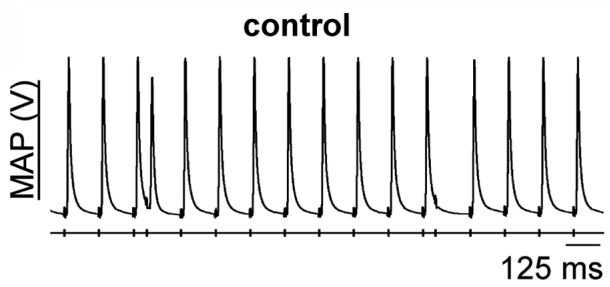

C

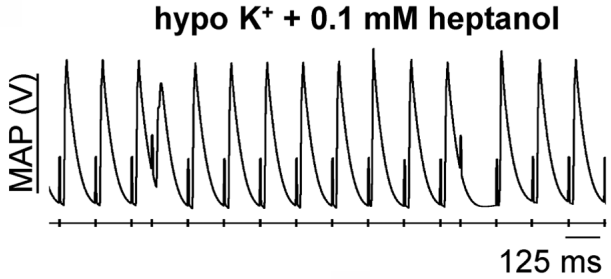

B

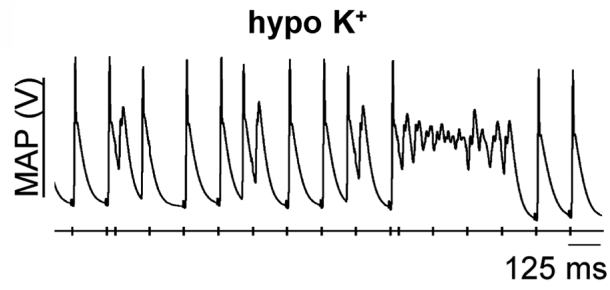

D

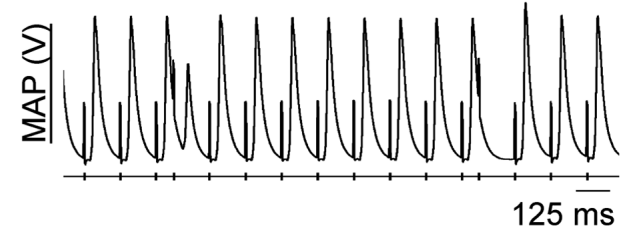

E

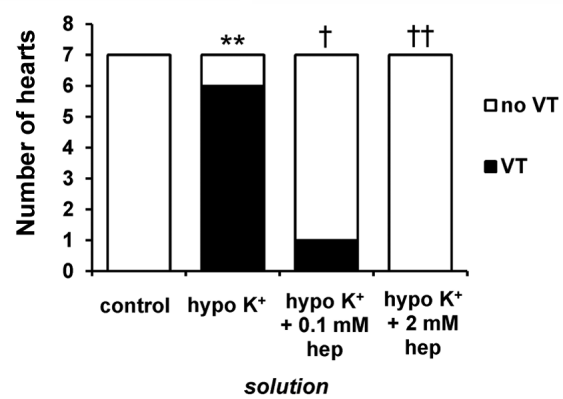

Figure 2. Representative monophasic action potential (MAP) recordings obtained during programmed electrical stimulation. (A) There was no evidence of provoked arrhythmias under control conditions. By contrast, (B) ventricular tachycardia (VT) was observed in under hypokalaemic conditions and inhibited by (C) 0.1 and (D) $2 \mathrm{mM}$ heptanol. (E) The proportion of hearts showing provoked VT was significantly increased by hypokalaemia from $0 / 7$ to $6 / 7$ hearts (Fisher's exact test, ${ }^{* *} \mathrm{P}<0.01$ ). This was reduced to $1 / 7$ and $0 / 7$ hearts following further introduction of $0.1\left({ }^{\dagger} \mathrm{P}<0.05\right)$ and $2 \mathrm{mM}(\dagger \mathrm{P}<0.01$ ) heptanol, respectively.

altering the incidence of VPBs (P>0.05) (Fig. 1D). Raising its concentration to $2 \mathrm{mM}$ prevented both VPBs in 5 hearts and $\mathrm{VT}$ in 6 hearts, respectively $(\mathrm{P}<0.05)$ (Fig. 1E).

The second set of experiments explored for re-entrant substrates using PES, imposing extrasystolic S2 stimuli following trains of regular S1 pacing stimuli. The S1S2 interval was initially at the BCL and subsequently reduced by $1 \mathrm{msec}$ with each cycle until the S2 stimuli produced either arrhythmic activity or refractoriness, with the latter indicating that the VERP had been reached. None of the hearts studied demonstrated evidence of arrhythmias under normokalaemic conditions (Fig. 2A; incidence summarised in Fig. 2E). By contrast, VT was induced by PES in 6/7 hearts during hypokalaemia (Fig. 2B) $(\mathrm{P}<0.01)$. Introduction of 0.1 (Fig. 2C) and $2 \mathrm{mM}$ (Fig. 2D) heptanol prevented VT from occurring in $5(\mathrm{P}<0.05)$ and 6 out of these 7 hearts $(\mathrm{P}<0.01)$, respectively.

Anti-arrhythmic effects of heptanol can be explained by VERP changes despite abnormal CVs and APDs. Previous studies using animal models of hypokalaemia have associated its pro-arrhythmic effects with reduced CVs (27), prolonged epicardial APDs, and prolonged or unaltered endocardial APDs, leading to decreased $\triangle \mathrm{APDs}$ given by the epicardial-endocardial difference (14) and decreased VERPs (15). By contrast, pro-arrhythmic effects of heptanol have been attributed to reduced CVs despite increased VERPs and normal APDs (19). To quantify the effect of heptanol on hypokalaemia-induced arrhythmogenesis, these parameters were determined from the data obtained in the aforementioned experiments $(n=7)$ and correlated with the arrhythmogenicity findings.

Firstly, epicardial activation latency was $17.4 \pm 0.8 \mathrm{msec}$ (Fig. 3A) under normokalaemic conditions, corresponding to a $\mathrm{CV}$ of $0.17 \pm 0.01 \mathrm{~m} / \mathrm{sec}$ (Fig. 3B), while endocardial activation latency was $17.4 \pm 1.4 \mathrm{msec}$ (Fig. 3C). These values were not altered by hypokalaemia alone or $0.1 \mathrm{mM}$ heptanol (ANOVA, $\mathrm{P}>0.05$ ). By contrast, $2 \mathrm{mM}$ heptanol increased epicardial and endocardial activation latencies to $29.0 \pm 2.3 \mathrm{msec}(\mathrm{P}<0.001)$ and $23.2 \pm 2.0 \mathrm{msec}(\mathrm{P}<0.05)$, respectively, and therefore decreased $\mathrm{CVs}$ to $0.11 \pm 0.01 \mathrm{~m} / \mathrm{sec}(\mathrm{P}<0.001)$. Epicardial activation latencies were not significantly different from their corresponding endocardial activation latencies under any of the aforementioned pharmacological conditions studied $(\mathrm{P}>0.05)$.

Secondly, epicardial $\mathrm{APD}_{90}$ was increased from $36.2 \pm 1.7$ to $55.7 \pm 2.0 \mathrm{msec}$ by hypokalaemia $(\mathrm{P}<0.001)$ (Fig. 4A), as were $\mathrm{APD}_{70}(\mathrm{P}<0.01)$ (Fig. 4B) and $\mathrm{APD}_{50}(\mathrm{P}<0.05)$ (Fig. 4C) but not $\mathrm{APD}_{30}(\mathrm{P}>0.05)$ (Fig. 4D). By contrast, endocardial $\mathrm{APD}_{90}$ (Fig. 4E), APD70 (Fig. 4F), $\operatorname{APD}_{50}$ (Fig. 4G) and $\mathrm{APD}_{30}$ (Fig. $\left.4 \mathrm{H}\right)(\mathrm{P}>0.05)$ were unaltered. These findings corresponded to decreased $\triangle \mathrm{APD}_{90}(\mathrm{P}<0.01)($ Fig. 5A) and $\triangle \mathrm{APD}_{70}(\mathrm{P}<0.05)($ Fig. $5 \mathrm{~B})$, but unaltered $\triangle \mathrm{APD}_{50}$ and $\triangle \mathrm{APD}_{30}$ ( $\mathrm{P}>0.05$ ) (Fig. 5C and D, respectively). Neither 0.1 nor $2 \mathrm{mM}$ heptanol further altered any of the $\mathrm{APD}_{\mathrm{x}}$ and therefore $\triangle \mathrm{APD}_{\mathrm{x}}$ ( $\mathrm{P}>0.05$ in all cases).

Finally, epicardial (Fig. 6A) and endocardial (Fig. 6B) VERPs were decreased from $44.5 \pm 4.0$ to $28.9 \pm 3.8 \mathrm{msec}$ $(\mathrm{P}<0.01)$ and from $38.2 \pm 1.6$ to $22.0 \pm 2.3 \mathrm{msec}(\mathrm{P}<0.001)$, 
A

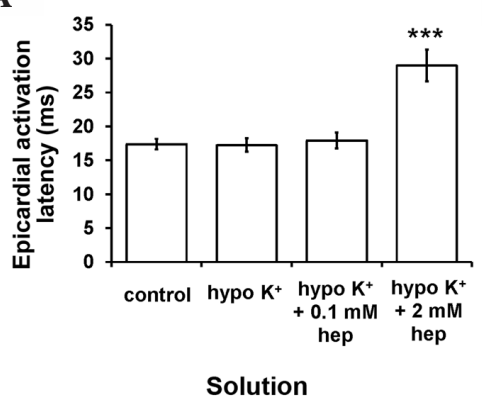

B

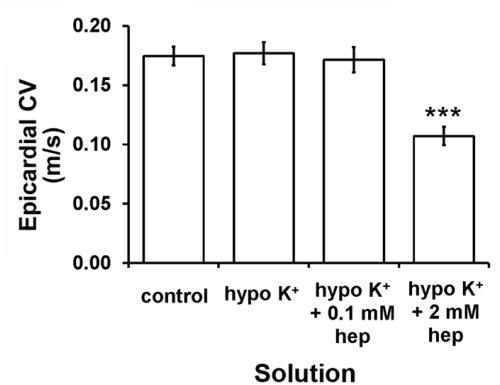

$\mathbf{C}$

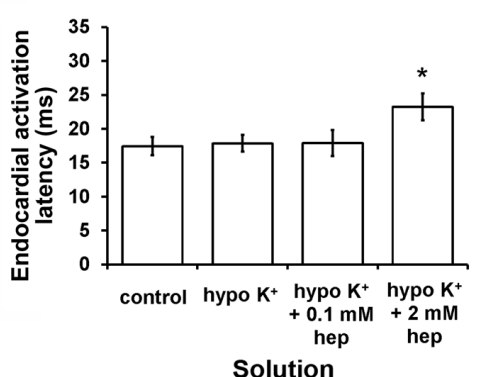

Figure 3. (A) Epicardial activation latency and (B) conduction velocity (CV), and (C) endocardial activation latency obtained during regular $8 \mathrm{~Hz}$ pacing. These were not altered by hypokalaemia whether prior or subsequent to introduction of $0.1 \mathrm{mM}$ heptanol (analysis of variance, P>0.05). By contrast, epicardial $\left({ }^{* * * *} \mathrm{P}<0.001\right)$ and endocardial $\left({ }^{*} \mathrm{P}<0.05\right)$ activation latencies were significantly increased by $2 \mathrm{mM}$ heptanol, corresponding to reduced $\left.\mathrm{CVs}{ }^{* * * *} \mathrm{P}<0.001\right)$. The epicardial activation latencies were not significantly different from the corresponding endocardial activation latencies under all pharmacological conditions studied $(\mathrm{P}>0.05)$.

A

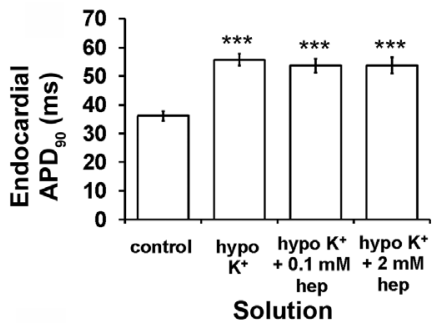

C

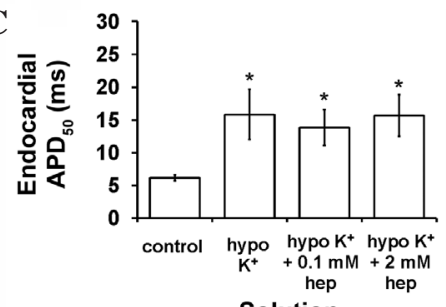

Solution

$\mathbf{E}$

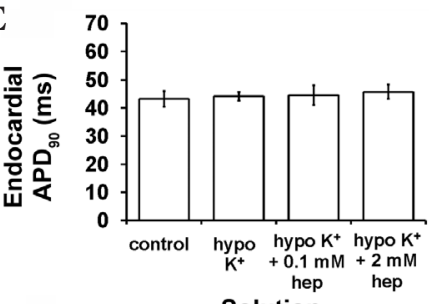

Solution

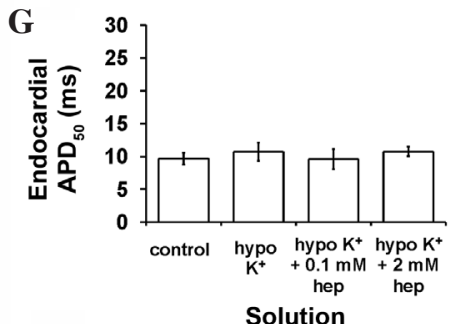

B

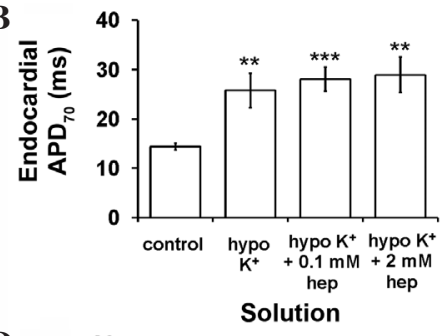

D
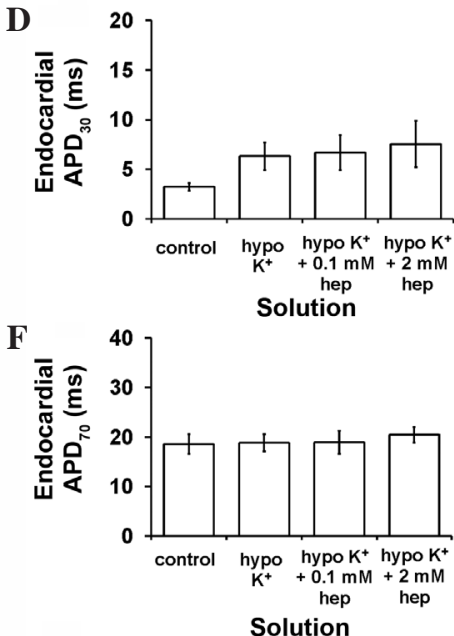

H

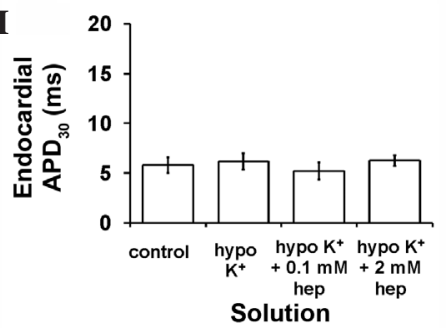

Figure 4. Epicardial action potential durations $\left(\mathrm{APD}_{\mathrm{x}}\right.$ ) at (A) $\mathrm{x}=90$, (B) 70 , (C) 50 and (D) $30 \%$ repolarisation obtained during regular $8 \mathrm{~Hz}$ pacing. Hypokalaemia increased epicardial $\mathrm{APD}_{90}$ (ANOVA, $\left.{ }^{* * * *} \mathrm{P}<0.001\right), \mathrm{APD}_{70}\left({ }^{* *} \mathrm{P}<0.01\right)$ and $\mathrm{APD}_{50}\left({ }^{*} \mathrm{P}<0.05\right)$ values but left $\mathrm{APD}_{30}$ unaltered $(\mathrm{P}>0.05) .0 .1$ and $2 \mathrm{mM}$ heptanol did not further alter these values $(\mathrm{P}>0.05)$. Endocardial $\mathrm{APD}_{\mathrm{x}}$ at $(\mathrm{E}) \mathrm{x}=90,(\mathrm{~F}) 70,(\mathrm{G}) 50$ and $(\mathrm{H}) 30 \%$ repolarisation obtained during regular $8 \mathrm{~Hz}$ pacing. Hypokalaemia treatment whether prior or subsequent to introduction of $0.1 \mathrm{mM}$ and $2 \mathrm{mM}$ heptanol did not further alter epicardial $\mathrm{APD}_{90}, \mathrm{APD}_{70}, \mathrm{APD}_{50}$ and $\mathrm{APD}_{30}$ (ANOVA, $\left.\mathrm{P}>0.05\right)$. ANOVA, analysis of variance.

respectively, during hypokalaemia. However, these were restored to $45.2 \pm 2.9$ and $38.5 \pm 4.6 \mathrm{msec}$, respectively $(\mathrm{P}<0.001$ and $\mathrm{P}<0.01$ ), by $0.1 \mathrm{mM}$ heptanol, which were indistinguishable from values obtained under normokalaemic conditions. By contrast, they were increased to $67.7 \pm 7.6(\mathrm{P}<0.05)$ and
$56.6 \pm 7.4 \mathrm{msec}(\mathrm{P}<0.05)$, respectively, at a higher concentration of $2 \mathrm{mM}$. Epicardial VERPs were significantly greater than the corresponding endocardial VERPs in the presence of $2 \mathrm{mM}$ heptanol $(\mathrm{P}<0.05)$, but not under any other pharmacological conditions $(\mathrm{P}>0.05)$. 
A

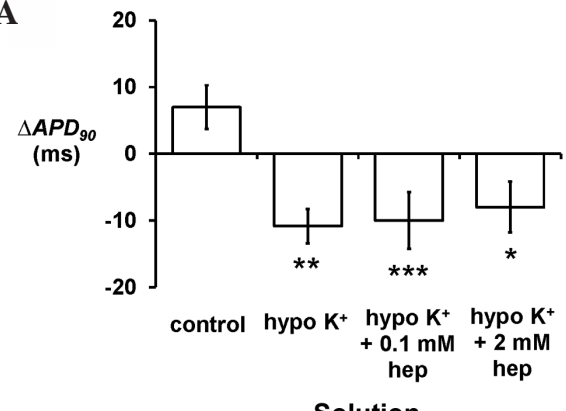

C

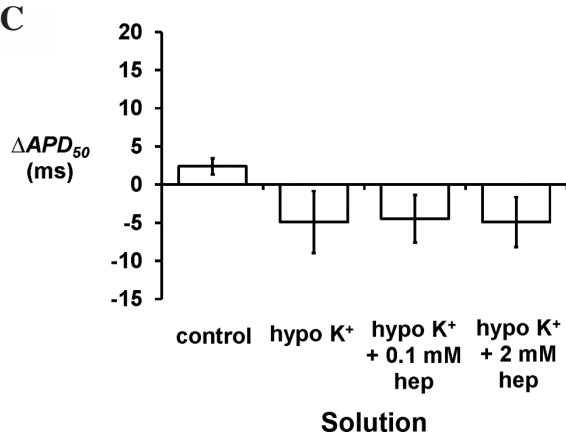

B

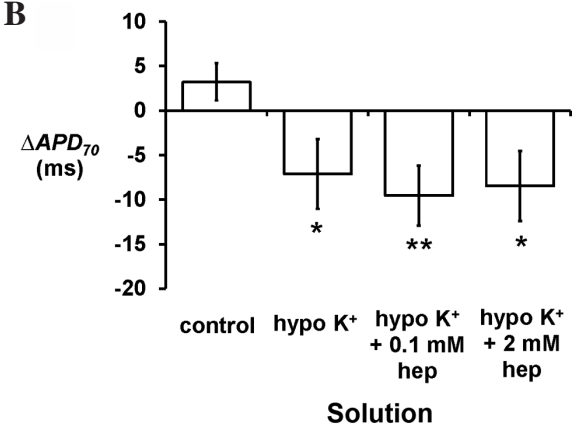

D

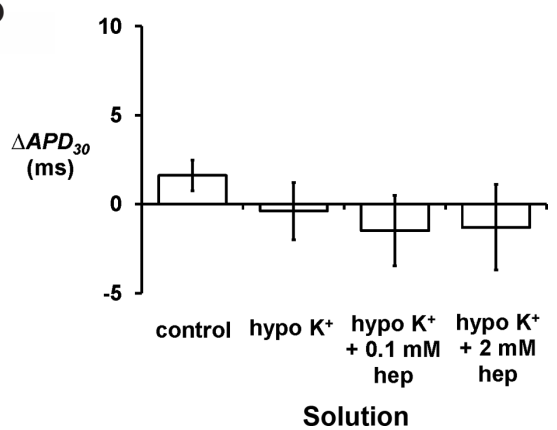

Figure 5. $\triangle \mathrm{APD}_{\mathrm{x}}$ given by endocardial $\mathrm{APD}_{\mathrm{x}}$ - epicardial $\mathrm{APD}_{\mathrm{x}}$ at (A) $\mathrm{x}=90$, (B) 70 , (C) 50 and (D) $30 \%$ repolarisation obtained during regular $8 \mathrm{~Hz}$ pacing. Hypokalaemia decreased $\triangle \mathrm{APD}_{90}$ (Student's t-test), $\triangle \mathrm{APD}_{70}$, but $\triangle \mathrm{APD}_{50}$ and $\triangle \mathrm{APD}_{30}$ were unaltered. These values were not further altered by 0.1 or $2 \mathrm{mM}$ heptanol $(\mathrm{P}>0.05)$. APD, action potential duration. $\left({ }^{*} \mathrm{P}<0.05,{ }^{* * *} \mathrm{P}<0.01,{ }^{* * * *} \mathrm{P}<0.001\right)$.
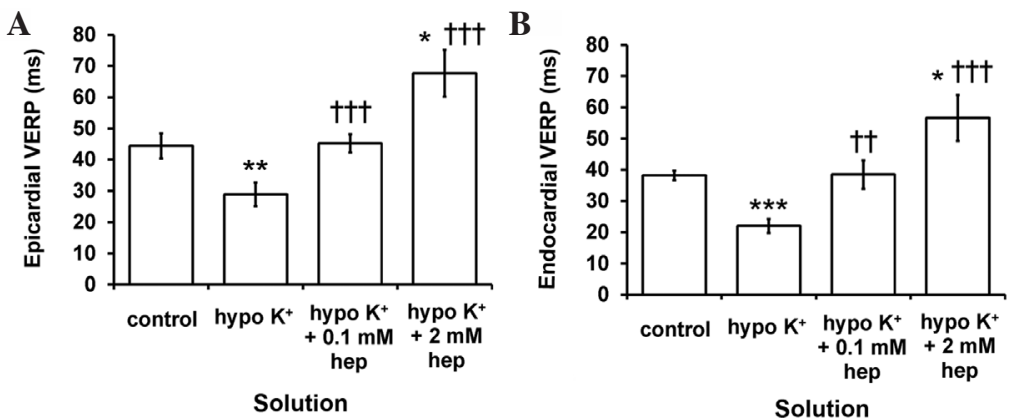

Figure 6. (A) Epicardial and (B) endocardial ventricular effective refractory periods (VERPs) obtained during programmed electrical stimulation. Significant differences from "normokalaemic and thypokalaemic values, respectively. Epicardial and endocardial VERPs were significantly reduced by hypokalaemia (analysis of variance, ${ }^{* *} \mathrm{P}<0.01$ and ${ }^{* * *} \mathrm{P}<0.001$ for epicardium and endocardium, respectively), but restored to normokalaemic values by $0.1 \mathrm{mM}$ heptanol $(\mathrm{P}>0.05)$. These were further increased by $2 \mathrm{mM}$ heptanol ( $\mathrm{P}<0.05)$. $\left.{ }^{+\mathrm{P}} \mathrm{P}<0.01,{ }^{+} \mathrm{P}<0.001\right)$.

Anti-arrhythmic effects of heptanol correlate directly with critical intervals and excitation wavelengths. Increases in critical intervals $\left(\mathrm{APD}_{90}\right.$ - VERP) either locally or across the myocardial wall (15) and decreases in excitation wavelengths (CV x VERP) $(19,28)$ have been associated with increased arrhythmic tendency. The local critical intervals for the epicardium and endocardium are given by epicardial $\mathrm{APD}_{90}$ - epicardial VERP and endocardial $\mathrm{APD}_{90}$ - endocardial VERP, respectively. The critical interval for transmural re-excitation of the epicardium by the endocardium is given by (endocardial latency + endocardial $\mathrm{APD}_{90}$ ) - (epicardial latency + epicardial VERP), and that of the endocardium by the epicardium is given by (epicardial latency + epicardial $\mathrm{APD}_{90}$ ) - (endocardial latency + endocardial VERP).

The local critical intervals obtained from the epicardium (Fig. 7A) were found to increase from $-8.3 \pm 4.3$ to $26.9 \pm 2.0 \mathrm{msec}$ by hypokalaemia $(\mathrm{P}<0.001)$. These were subsequently reduced by $0.1 \mathrm{mM}(\mathrm{P}<0.05)$ and restored to normokalaemic values by $2 \mathrm{mM}$ heptanol $(\mathrm{P}>0.05)$. Similar patterns of changes were observed for local critical intervals obtained from the endocardium (Fig. 7B), and for transmural critical intervals reflecting the period permitting re-excitation of the endocardium by the epicardium (Fig. 7C) and of the epicardium by the endocardium (Fig. 7D). Excitation wavelengths (Fig. 7E) were significantly reduced from $7.9 \pm 1.1$ to $5.1 \pm 0.3 \mathrm{~mm}$ by hypokalaemia $(\mathrm{P}<0.05)$, and returned to normokalaemic values by 0.1 and $2 \mathrm{mM}$ heptanol $(\mathrm{P}>0.05)$.

Heptanol does not alter APD or CV restitution properties during hypokalaemia. Previous studies have associated increased arrhythmogenicity with increases in maximum $\mathrm{APD}_{90}$ restitution gradients, critical diastolic intervals (DIs and $\mathrm{DI}_{\text {crit }}$ ), and maximum $\mathrm{APD}_{90}$ reduction between the longest and shortest S1S2 intervals studied under hypokalaemic conditions (29). In other models systems, by contrast, increased arrhythmogenicity was attributed to abnormal CV 
Table I. Parameters for epicardial $\mathrm{APD}_{90}$ restitution curves obtained during programmed electrical stimulation.

\begin{tabular}{lccr}
\hline Condition & $\mathrm{y}_{0}, \mathrm{msec}$ & $\mathrm{A}, \mathrm{msec}$ & $\tau, \mathrm{msec}$ \\
\hline Control & $45.2 \pm 2.9$ & $-23.2 \pm 3.6$ & $21.7 \pm 4.4$ \\
Hypo K & $51.1 \pm 2.0$ & $-108.3 \pm 62.6$ & $12.6 \pm 4.5$ \\
Hypo K ${ }^{+}+0.1 \mathrm{mM}$ heptanol & $55.5 \pm 2.2$ & $-82.1 \pm 40.0$ & $4.7 \pm 1.0$ \\
Hypo K $+2 \mathrm{mM}$ heptanol & $60.0 \pm 5.7$ & $-180.1 \pm 118.0$ & $11.2 \pm 4.8$ \\
\hline
\end{tabular}

APD, action potential duration.

Table II. Parameters for endocardial $\mathrm{APD}_{90}$ restitution curves obtained during programmed electrical stimulation.

\begin{tabular}{llrr}
\hline Condition & $\mathrm{y}_{0}, \mathrm{msec}$ & $\mathrm{A}, \mathrm{msec}$ & $\tau, \mathrm{msec}$ \\
\hline Control & $43.6 \pm 3.6$ & $-124.6 \pm 97.8$ & $39.0 \pm 13.6$ \\
Hypo K & $54.3 \pm 19.8$ & $-36.6 \pm 18.9$ & $20.4 \pm 26.5$ \\
Hypo K $+0.1 \mathrm{mM}$ heptanol & $52.0 \pm 9.8$ & $-48.5 \pm 25.0$ & $50.9 \pm 42.4$ \\
Hypo K +2 mM heptanol & $62.5 \pm 22.3$ & $-31.0 \pm 20.1$ & $15.4 \pm 34.9$ \\
\hline
\end{tabular}

APD, action potential duration.

restitution. Thus, increased maximum $\mathrm{CV}$ restitution gradients were observed in untreated rabbit hearts (30); increased time constants of the fitted restitution curves (i.e., decreased CV restitution gradients) was demonstrated in ion channel models and diacetyl monoxime-treated rabbit hearts $(31,32)$; increase in maximal CV reductions between the longest and shortest S1S2 intervals studied was seen in D600-treated rabbit hearts (24).

In the present study, restitution curves were constructed using the PES data obtained above, by plotting $\mathrm{APD}_{90}$ or $\mathrm{CV}$ against the preceding DI, and were then fitted with an exponential function of the form $\mathrm{y}=\mathrm{y}_{0}+\mathrm{Ae}^{-\mathrm{x} / \tau}$ by a least-squares method using a Levenberg-Marquardt algorithm. y represents either $\mathrm{APD}_{90}$ or $\mathrm{CV}$, and $\mathrm{x}$ represents $\mathrm{DI}$, whereas $\mathrm{y}_{0}$, $\mathrm{A}$ and $\tau$ are constants. The gradient is given by

$$
\frac{d y}{d x}=\frac{A}{\tau} e^{-x / \tau}
$$

assuming its maximal value at the shortest S1S2 interval

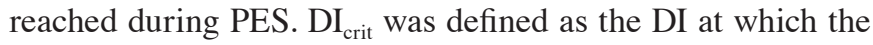
gradient of the fitted function reached unity. Maximum $\mathrm{APD}_{90}$ or $\mathrm{CV}$ reduction, reflecting heterogeneity in restitution, was defined as the difference between values obtained at the longest S1S2 interval and those obtained at the shortest S1S2 interval.

Fig. 8 shows examples of $\mathrm{APD}_{90}$ restitution curves (solid lines, left ordinates) and their gradients (broken lines, right axes) obtained at the epicardium (Fig. 8A-D) and the endocardium (Fig. 8E-H) under normokalaemic and hypokalaemic conditions prior and subsequent to the introduction of 0.1 or $2 \mathrm{mM}$ heptanol; fitted parameters summarised in Tables I and II, respectively. APD ${ }_{90}$ decreased with decreasing DIs under all pharmacological conditions studied.

The maximal $\mathrm{APD}_{90}$ restitution gradients (Fig. 9A), $\mathrm{DI}_{\text {crit }}$ (Fig. 9B) and maximum $\mathrm{APD}_{90}$ reductions (Fig. 9C) in the epicardium were increased by hypokalaemia $(\mathrm{P}<0.05, \mathrm{P}<0.01$ and $\mathrm{P}<0.05$, respectively). Introduction of 0.1 or $2 \mathrm{mM}$ heptanol restored maximum $\mathrm{APD}_{90}$ reductions to normokalaemic values ( $P>0.05)$, but did not further alter maximum $\mathrm{APD}_{90}$ restitution gradients or $\mathrm{DI}_{\text {crit }}$. All these corresponding parameters in the endocardium remained unaltered (Fig. 9D-F) during hypokalaemia conditions whether prior or subsequent to introduction of 0.1 or $2 \mathrm{mM}$ heptanol ( $\mathrm{P}>0.05$ in all cases).

Fig. 10 progresses to show examples of epicardial CV restitution curves (solid lines, left ordinates) and their gradients (broken lines, right axes) obtained under normokalaemic and hypokalaemic conditions prior and subsequent to introduction of 0.1 and $2 \mathrm{mM}$ heptanol (Fig. 10A-D), with fitted parameters summarised in Table III. However, there was no difference in maximum CV restitution gradients (Fig. 10E), time constants $\tau$ of the restitution curves (Fig. 10F) or maximum CV reductions (Fig. 10G) between these pharmacological conditions $(\mathrm{P}>0.05)$.

Taken together, all the above findings demonstrate that hypokalaemia elicited VPBs and VT, associated with prolonged epicardial $\mathrm{APD}_{90}$, unaltered endocardial $\mathrm{APD}_{90}$, and reduced epicardial and endocardial VERPs despite unaltered activation latencies and CVs. These changes corresponded to decreased $\triangle \mathrm{APD}$, increased critical intervals and reduced excitation wavelengths. Dynamic substrates in the form of abnormal APD restitution also appeared to have a role in its arrhythmogenesis, as exemplified by increases in maximum $\mathrm{APD}_{90}$ restitution gradients, $\mathrm{DI}_{\text {crit }}$ and maximum $\mathrm{APD}_{90}$ reductions observed during PES. However, CV restitution did not have an apparent contribution, as maximum $\mathrm{CV}$ restitution gradients, time constants of $\mathrm{CV}$ restitution curves and maximum $\mathrm{CV}$ reductions all remained unchanged. Heptanol at $0.1 \mathrm{mM}$ prevented VT by normalising VERPs, resulting in normal critical intervals and normal excitation wavelengths. 
Table III. Parameters for conduction velocity restitution curves obtained during programmed electrical stimulation.

\begin{tabular}{lllr}
\hline Condition & $\mathrm{y}_{0}, \mathrm{~m} / \mathrm{sec}$ & $\mathrm{A}, \mathrm{m} / \mathrm{sec}$ & $\tau, \mathrm{msec}$ \\
\hline Control & $0.20 \pm 0.01$ & $-0.62 \pm 0.420$ & $16.7 \pm 4.9$ \\
Hypo K & $0.20 \pm 0.01$ & $-0.15 \pm 0.012$ & $17.1 \pm 3.0$ \\
Hypo K & $0.1 \mathrm{mM}$ heptanol & $-0.15 \pm 0.027$ & $13.5 \pm 1.6$ \\
Hypo K & $0.16 \pm 0.01$ & $-0.18 \pm 0.082$ & $15.1 \pm 5.2$ \\
\hline
\end{tabular}

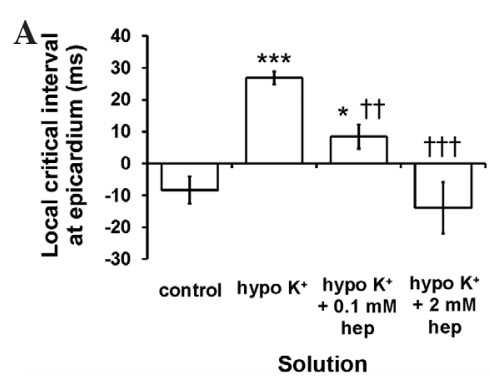

D

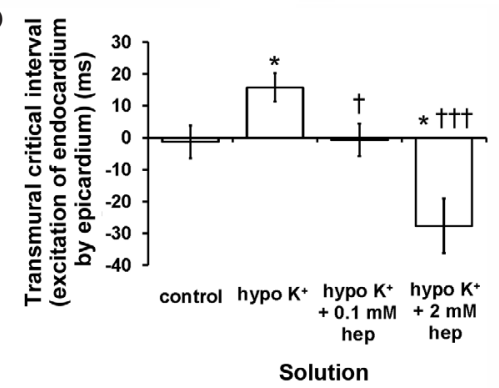

B

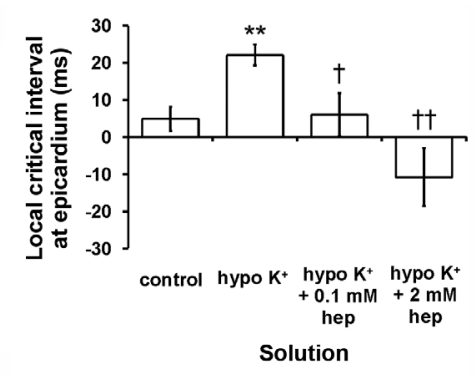

$\mathbf{E}$

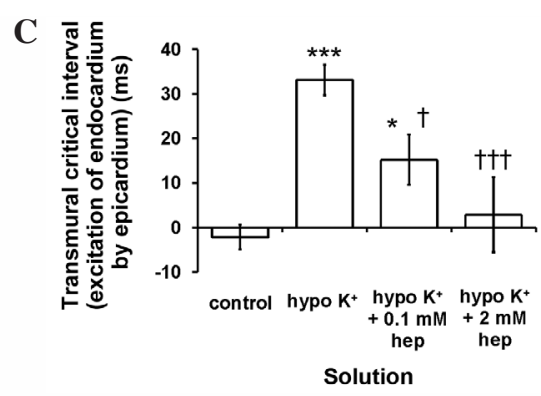

Solution

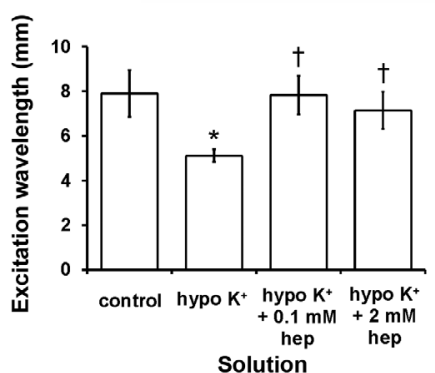

Figure 7. (A-D) Critical intervals [action potential durations (APD) 90 $_{0}$ - ventricular effective refractory periods (VERP)] and (E) excitation wavelength [conduction velocity $(\mathrm{CV}) \mathrm{x}$ ventricular effective refractory periods (VERP)]. Significant differences from *normokalaemic and thypokalaemic values, respectively. Local critical intervals obtained from the (A) epicardium were significantly increased by hypokalaemia (Student's t-test, $\left.{ }^{* * * *} \mathrm{P}<0.001\right)$ and subsequently reduced by $0.1 \mathrm{mM}\left({ }^{\dagger} \mathrm{P}<0.01 ;{ }^{\dagger} \mathrm{P}<0.05\right)$ and $2 \mathrm{mM}$ heptanol $\left({ }^{\dagger+} \mathrm{P}<0.001\right)$. Those obtained from the (B) endocardium, and transmural critical intervals for re-excitation of the endocardium by the (C) epicardium and that of the epicardium by the (D) endocardium exhibited similar patterns of changes. (E) Excitation wavelength was significantly reduced by hypokalaemia (analysis of variance, ${ }^{*} \mathrm{P}<0.05$ ) but returned to normokalaemic values following introduction of 0.1 or $2 \mathrm{mM}$ heptanol $(\mathrm{P}>0.05)$.

At $2 \mathrm{mM}$, it prevented VPBs and VT by increasing VERPs despite reducing $\mathrm{CVs}$, which corresponded to reduced critical intervals and increased excitation wavelengths. These anti-arrhythmic effects observed at heptanol concentrations were associated with restoration of maximum $\mathrm{APD}_{90}$ reductions to normokalaemic values despite no further changes to APDs or the remaining $\mathrm{APD}_{90}$ and $\mathrm{CV}$ restitution parameters.

\section{Discussion}

Ventricular arrhythmias represent a significant cause of sudden cardiac death, accounting for around 60,000 fatalities in the UK (33), 200,000 fatalities in the US (34) and 4-5 million fatalities worldwide (35) per year. Hypokalaemia is a cause of electrocardiographic QT prolongation, reflecting delayed action potential repolarisation (4), which predisposes to a particular form of polymorphic VT termed torsade de pointes (5). It is the most common electrolyte abnormality identified in hospitalised patients (36) and therefore represents an important cause of arrhythmias observed in clinical practice (37).

Ventricular arrhythmic properties of hypokalaemic Langendorff-perfused mouse hearts were examined in the presence and absence of 0.1 or $2 \mathrm{mM}$ heptanol. This is an agent that reversibly inhibits gap junctions at concentrations $<1 \mathrm{mM}$ and also sodium channels $\geq 2 \mathrm{mM}(16,18)$. Previous studies have described pro-arrhythmic effects of hypokalaemia $(14,15,29)$ or heptanol (19). Heptanol (2 $\mathrm{mM})$ is known to induce ventricular tachy-arrhythmias through decreases in CVs, despite also increasing VERPs and leaving APDs unchanged under normokalaemic conditions. The central hypothesis here is that changes in VERPs produced by heptanol could compensate for prolonged APDs and thereby abolish arrhythmogenesis produced by hypokalaemia. This may be explicable by changes in critical intervals given by APD - VERP and excitation wavelengths given by $\mathrm{CV} x \mathrm{VERP}$.

Monophasic action potential (MAP) recordings were obtained from the left ventricular epicardium or endocardium. Previous studies have shown that APDs derived from such recordings reflect the time courses of the cellular action potential obtained from single cells $(21,38,39)$. Two different stimulation protocols were used. Firstly, regular pacing at $8 \mathrm{~Hz}$, close to the in vivo heart rate (40), was used to detect spontaneous arrhythmogenesis. This revealed VPBs and VT during hypokalaemia in an absence of alterations in $\mathrm{CV}$, in 
A

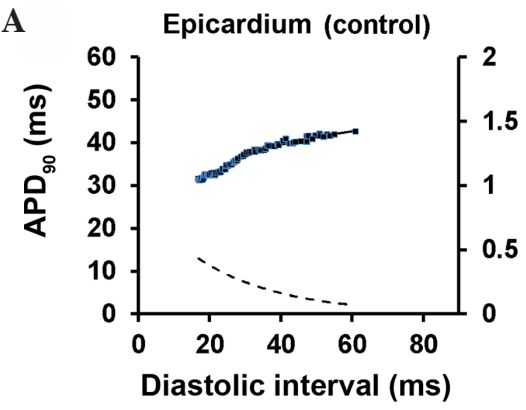

C Epicardium (hypo $\mathrm{K}^{+}+0.1 \mathrm{mM}$ hep)

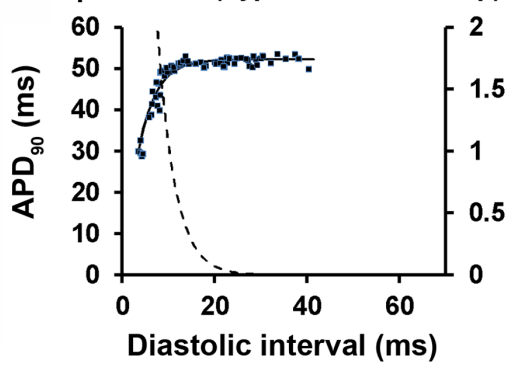

E

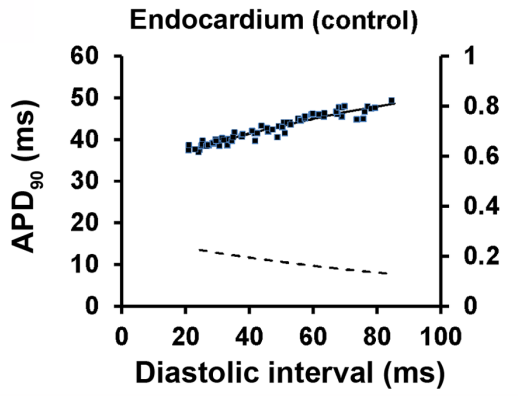

G

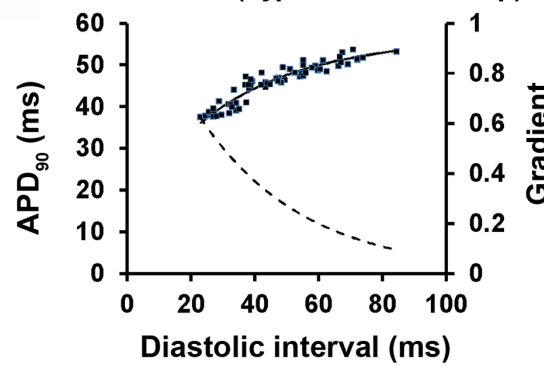

B

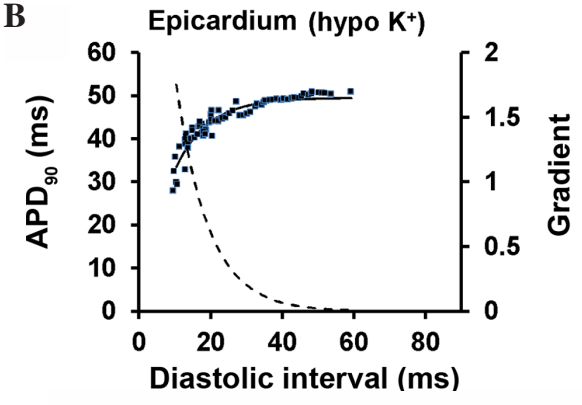

D Epicardium (hypo $\mathrm{K}^{+}+2 \mathrm{mM}$ hep)

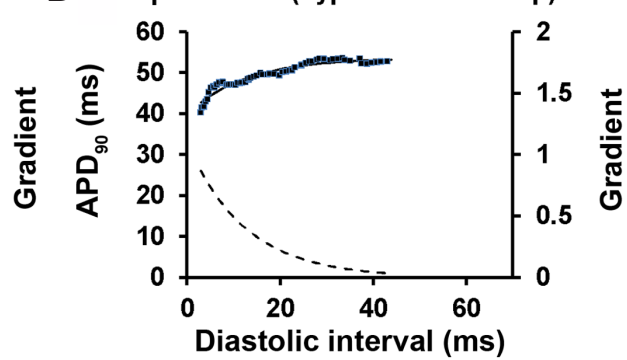

F

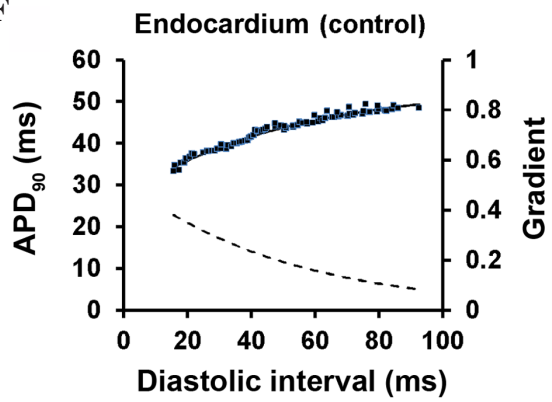

$\mathrm{H}$ Endocardium (hypo $\mathrm{K}^{+}+2 \mathrm{mM}$ hep)

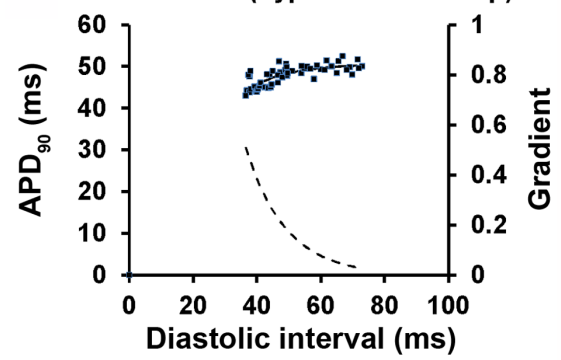

Figure 8. Restitution curves plotting action potential durations (APD) $)_{90}$ against preceding diastolic interval (DI) obtained from the (A-D) epicardium and (E-H) endocardium under control and hypokalaemic conditions prior and subsequent to the introduction of 0.1 or $2 \mathrm{mM}$ heptanol. Curves were fitted with mono-exponential growth functions obtained by least-squares fitting to the values of $\mathrm{APD}_{90}$ and DI (solid lines, left ordinates). Gradients were obtained by differentiation of the fitted functions (broken lines, right axes).

agreement with previous findings (14). Heptanol $(0.1 \mathrm{mM})$ prevented VT without affecting VPBs, but at $2 \mathrm{mM}$ prevented both despite a reduction in CV.

Secondly, PES procedures, which delivered increasing premature S2 stimuli following trains of regularly-timed S1 stimuli, were used to detect the presence of re-entrant substrates, as has been performed in clinical practice (25). This protocol also allowed exploration of the role of CV and APD restitution in hypokalaemia-induced arrhythmogenicity $(29,30,41)$. During hypokalaemia, an increase in the proportion of hearts showing provoked VT was observed. This was associated with prolonged epicardial, but unaltered endocardial APDs and reduced epicardial and endocardial VERPs, in an absence of alterations in CVs. Epicardial APD restitution gradients and critical diastolic intervals were increased. The difference between epicardial
APD obtained from the longest S1S2 interval and APD obtained from the shortest S1S2 interval studied was increased, reflecting an increased heterogeneity in APD restitution (24). The latter finding could be explained by reduced VERPs, which would allow shorter S1S2 intervals and therefore shorter APDs to be attained. Endocardial APD restitution gradients, critical diastolic intervals and APD differences were all unaltered. CV restitution gradients, restitution time constants and restitution heterogeneity were not affected. Notably, these results obtained during extrasystolic stimulation are in agreement with previous findings that were determined by a dynamic pacing protocol (29). This confirms the value of using PES in restitution analysis, as previously discussed (42). Such a protocol has the advantage of safety over dynamic pacing in a clinical setting, which can induce myocardial ischaemia from tachycardia pacing (42). 
A

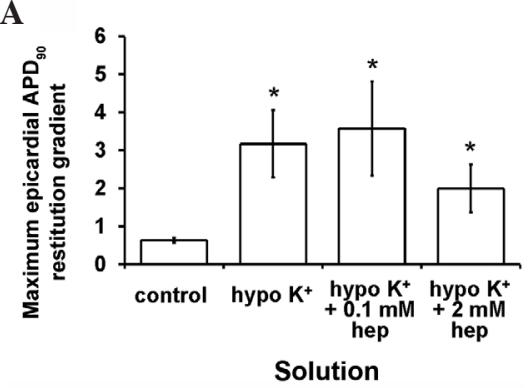

D

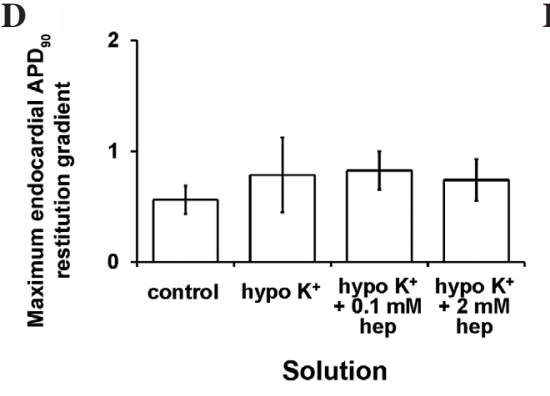

B

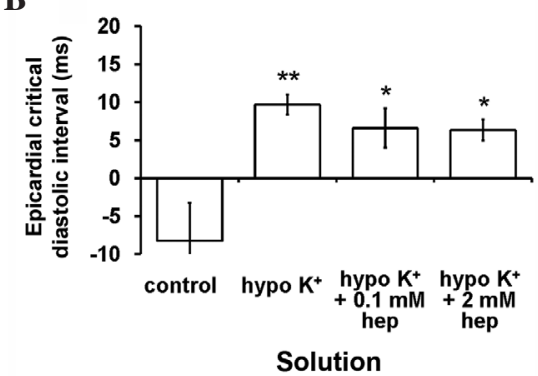

$\mathbf{E}$

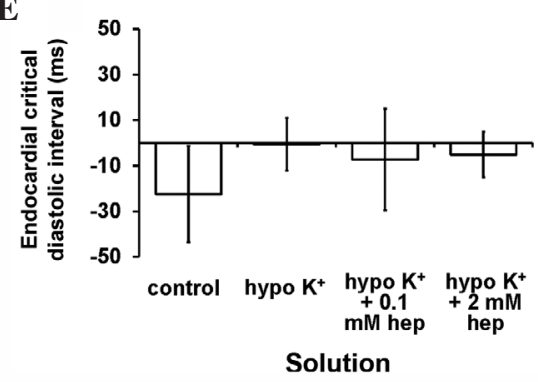

C

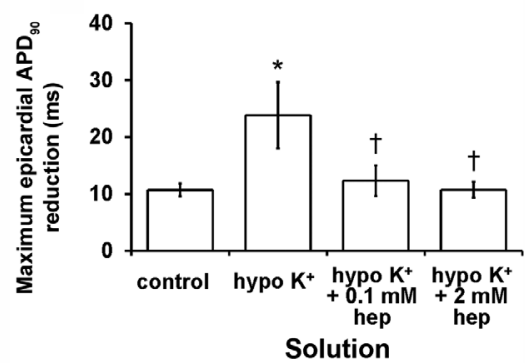

F

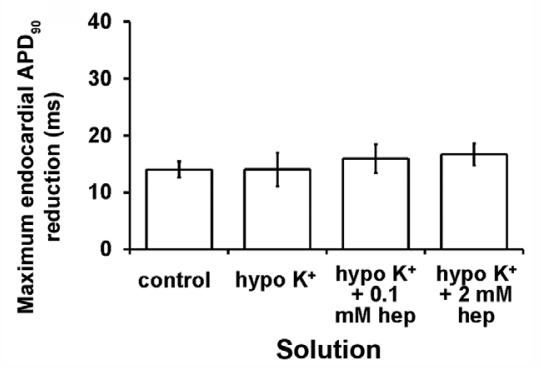

Figure 9. Maximum action potential durations (APD) ${ }_{90}$ restitution gradients, critical diastolic intervals and maximum $\mathrm{APD}_{90}$ reductions obtained from the (A-C) epicardium and (D-F) endocardium. All three parameters were increased by hypokalaemia $\left({ }^{*} \mathrm{P}<0.05,{ }^{* *} \mathrm{P}<0.01\right.$ and ${ }^{*} \mathrm{P}<0.05$, respectively). Of these, maximum $\mathrm{APD}_{90}$ reductions were restored to normokalaemic values $(\mathrm{P}>0.05)$, whereas maximum $\mathrm{APD}_{90}$ restitution gradients and critical diastolic intervals were not further altered by 0.1 or $2 \mathrm{mM}$ heptanol. All three parameters obtained from the endocardium were unaltered by hypokalaemia whether prior and subsequent to the introduction of 0.1 or $2 \mathrm{mM}$ heptanol $\left(\mathrm{P}>0.05\right.$ in all cases). $\left({ }^{\dagger} \mathrm{P}<0.05\right)$.

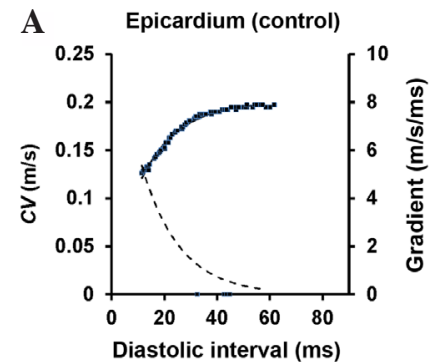

$\mathbf{E}$

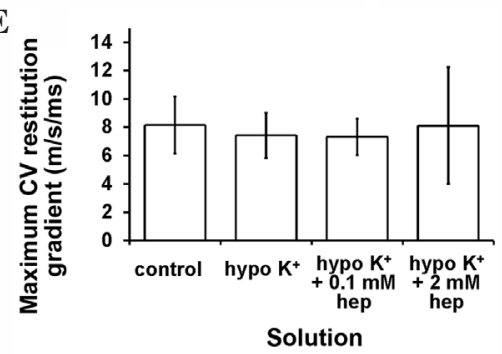

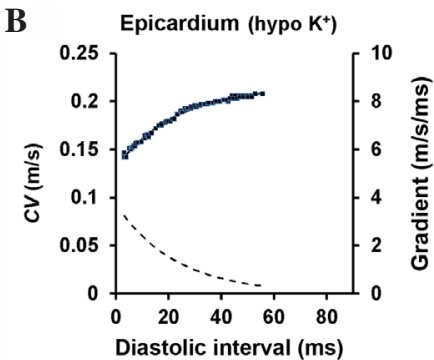

$\mathbf{F}$

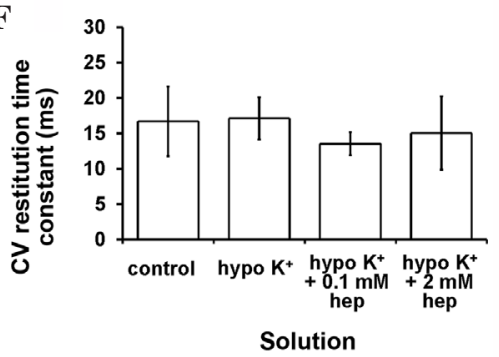

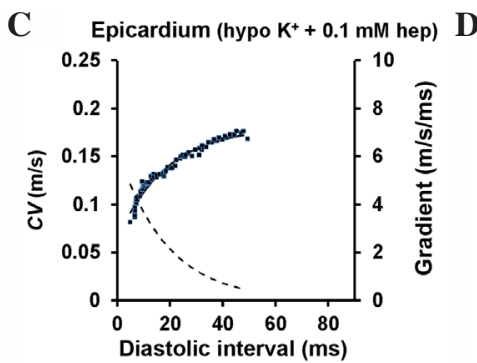
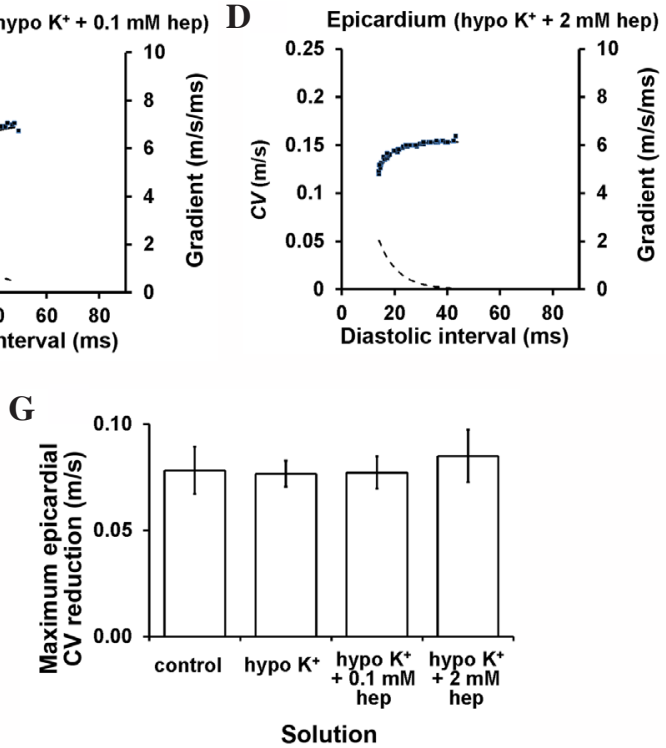

Figure 10. Restitution curves plotting conduction velocity (CV) against preceding diastolic interval (DI) obtained under (A) control and hypokalaemic conditions (B) prior and subsequent to the introduction of (C) 0.1 or (D) $2 \mathrm{mM}$ heptanol. Curves were fitted with mono-exponential growth functions obtained by least-squares fitting to the values of CV and DI (solid lines, left ordinates). Gradients were obtained by differentiation of the fitted functions (broken lines, right axes). (E) Maximum CV restitution gradients, (F) time constants of restitution curves and (G) maximum CV reductions. None of these parameters was altered by hypokalaemia whether prior or subsequent to the introduction of 0.1 or $2 \mathrm{mM}$ heptanol $(\mathrm{P}>0.05)$.

Together, these changes resulted in a negative $\triangle \mathrm{APD}_{90}$ given by endocardial $\mathrm{APD}_{90}$ - epicardial $\mathrm{APD}_{90}$, suggesting a reversal of transmural repolarisation gradients, which has previously been associated with VT (14). The excitation wavelength given by CV x VERP was decreased, thereby predisposing the hearts to circus-type re-entry (43). Furthermore, there was an increase in the critical interval given by APD - VERP, which would increase the likelihood of re-excitation occurring prior to full action potential repolarisation (15). This may reflect an underlying re-entrant mechanism previously termed prolonged repolarisation-dependent re-excitation (44) and phase 2 re-entry (45) described in Brugada syndrome.

Heptanol $(0.1 \mathrm{mM})$ prevented the induction of VT and reversed ERP changes, despite leaving APD abnormalities and $\mathrm{CV}$ unaffected. This in turn led to the return of the excitation wavelength and critical interval to normokalaemic values, 
consistent with its effects in preventing VT. The fact that VPBs persisted can be explained by prolonged APDs despite normal VERPs. This would still permit the re-activation of L-type calcium currents, previously implicated in the development of early after-depolarisations and subsequently induced triggered activity (46-48). Heptanol (2 mM) also prevented VT, which is associated with increased ERPs. This is despite persistently prolonged APDs and an additional slowing in $\mathrm{CV}$, expected to increase arrhythmogenicity. These changes corresponded to increased excitation wavelengths and decreased critical intervals, both of which would decrease arrhythmogenicity. At this concentration, heptanol also prevented VPBs, which can be explained by increased VERPs; this would prevent EADs from eliciting premature action potentials in the myocardium that has not recovered from refractoriness. In the presence of either 0.1 or $2 \mathrm{mM}$ heptanol, APD restitution properties remained abnormal and $\mathrm{CV}$ restitution was not affected during hypokalaemia.

The above findings obtained during PES contrast with previous observations during normokalaemia in which no pro-arrhythmic effects were observed at $0.1 \mathrm{mM}$, but inducible VT was detected at $2 \mathrm{mM}$ heptanol (19). These differences can be explained by $2 \mathrm{mM}$ heptanol reducing CV more than it increases ERP with a consequent decrease in excitation wavelength. The anti-arrhythmic action of heptanol in hypokalaemia observed here therefore complements previous demonstrations of its other beneficial effects in reducing infarct size in mouse and rat hearts $(49,50)$ and preventing ventricular arrhythmias induced by ischaemia in rat hearts $(50,51)$. A limitation of the present study is that the mechanisms of VPBs and VT cannot be determined. However, hypokalaemia is known to elicit EADs and the VPBs observed may reflect underlying triggered activity. VT could be due to re-entry, although it could theoretically be a run of VPBs from focal activity. If VT is caused by re-entry, the mechanism is uncertain, whether it is due to circus-type, phase 2 or spiral wave re-entry. However, premature activation by phase 2 re-entry (or indeed a VPB from triggered activity) can in turn facilitate the induction of circus-type movement (52).

Protective effects of gap junction in reducing infarct size as well as preventing arrhythmogenesis produced by ischaemia have previously been described $(49,50)$. Theoretical work has shown that in non-uniform tissue, mild loss of gap junction function paradoxically increases $\mathrm{CV}$, thereby improving the safety margin of conduction (53). Thus, this may remove unidirectional blocks, converting them into bilateral conduction, which would protect against arrhythmogenesis (54-56). In the present study, the experiments show that in addition to the effects on conduction, the gap junction uncoupler heptanol also influences VERP and this may underlie its anti-arrhythmic action in hypokalaemia. This occurred despite a lack of correction of the repolarisation abnormalities (prolonged APD and increased APD restitution steepness), even in the presence of reduced $\mathrm{CV}$, which alone is pro-arrhythmic (19).

The proof of concept demonstrated here is that although the arrhythmic risk of hypokalaemia has traditionally been associated with prolonged QT interval (57) and increased QT dispersion (58), increasing VERPs can prevent arrhythmias even when such repolarisation abnormalities persist. Heptanol (2 $\mathrm{mM})$ is known to induce VT under normokalaemic conditions, at a lower concentration of $0.1 \mathrm{mM}$, however, it had no pro-arrhythmic effects (19). Its possible therapeutic effects therefore warrant further investigation.

\section{Acknowledgements}

GT was supported by the Biotechnology and Biological Sciences Research Council (BBSRC) CASE Doctoral Training Award.

\section{References}

1. Saez JC, Berthoud VM, Branes MC, Martinez AD and Beyer EC: Plasma membrane channels formed by connexins: Their regulation and functions. Physiol Rev 83: 1359-1400, 2003.

2. Kanno S and Saffitz JE: The role of myocardial gap junctions in electrical conduction and arrhythmogenesis. Cardiovasc Pathol 10: 169-177, 2001.

3. Antzelevitch C and Burashnikov A: Overview of basic mechanisms of cardiac arrhythmia. Card Electrophysiol Clin 3: 23-45, 2011.

4. Choy AM, Lang CC, Chomsky DM, Rayos GH, Wilson JR and Roden DM: Normalization of acquired QT prolongation in humans by intravenous potassium. Circulation 96: 2149-2154, 1997.

5. Krikler DM and Curry PV: Torsade De Pointes, an atypical ventricular tachycardia. Br Heart J 38: 117-120, 1976.

6. The Cardiac Arrhythmia Suppression Trial (CAST) Investigators: Preliminary report: Effect of encainide and flecainide on mortality in a randomized trial of arrhythmia suppression after myocardial infarction. N Engl J Med 321: 406-412, 1989.

7. Wolbrette DL: Risk of proarrhythmia with class III antiarrhythmic agents: Sex-based differences and other issues. Am J Cardiol 91: 39D-44D, 2003.

8. Fujiki A, Tani M, Yoshida S and Inoue H: Electrophysiologic mechanisms of adverse effects of class I antiarrhythmic drugs (cibenzoline, pilsicainide, disopyramide, procainamide) in induction of atrioventricular re-entrant tachycardia. Cardiovasc Drugs Ther 10: 159-166, 1996.

9. Nattel S and Carlsson L: Innovative approaches to anti-arrhy thmic drug therapy. Nat Rev Drug Discov 5: 1034-1049, 2006.

10. Xing D, Kjølbye AL, Nielsen MS, Petersen JS, Harlow KW, Holstein-Rathlou NH and Martins JB: ZP123 increases gap junctional conductance and prevents reentrant ventricular tachycardia during myocardial ischemia in open chest dogs. J Cardiovasc Electrophysiol 14: 510-520, 2003.

11. Papp R, Gönczi M, Kovács M, Seprényi G and Végh A: Gap junctional uncoupling plays a trigger role in the antiarrhythmic effect of ischaemic preconditioning. Cardiovasc Res 74: 396-405, 2007.

12. Sabir IN, Killeen MJ, Grace AA and Huang CL: Ventricular arrhythmogenesis: Insights from murine models. Prog Biophys Mol Biol 98: 208-218, 2008.

13. De Vuyst E, Boengler K, Antoons G, Sipido KR, Schulz R and Leybaert L: Pharmacological modulation of connexin-formed channels in cardiac pathophysiology. Br J Pharmacol 163: 469-483, 2011.

14. Killeen MJ, Thomas G, Gurung IS, Goddard CA, Fraser JA, Mahaut-Smith MP, Colledge WH, Grace AA and Huang CL: Arrhythmogenic mechanisms in the isolated perfused hypokalaemic murine heart. Acta Physiol (Oxf) 189: 33-46, 2007.

15. Sabir IN, Fraser JA, Killeen MJ, Grace AA and Huang CL: The contribution of refractoriness to arrhythmic substrate in hypokalemic Langendorff-perfused murine hearts. Pflugers Arch 454: 209-222, 2007.

16. Christ GJ, Spektor M, Brink PR and Barr L: Further evidence for the selective disruption of intercellular communication by heptanol. Am J Physiol 276: H1911-H1917, 1999.

17. Rüdisüli A and Weingart R: Electrical properties of gap junction channels in guinea-pig ventricular cell pairs revealed by exposure to heptanol. Pflugers Arch 415: 12-21, 1989.

18. Nelson WL and Makielski JC: Block of sodium current by heptanol in voltage-clamped canine cardiac Purkinje cells. Circ Res 68: 977-983, 1991

19. Tse G, Hothi SS, Grace AA and Huang CL: Ventricular arrhythmogenesis following slowed conduction in heptanol-treated, Langendorff-perfused mouse hearts. J Physiol Sci 62: 79-92, 2012. 
20. Balasubramaniam R, Grace AA,Saumarez RC, Vandenberg JI and Huang CL: Electrogram prolongation and nifedipine-suppressible ventricular arrhythmias in mice following targeted disruption of KCNE1. J Physiol 552: 535-546, 2003.

21. Knollmann BC, Katchman AN and Franz MR: Monophasic action potential recordings from intact mouse heart: Validation, regional heterogeneity, and relation to refractoriness. J Cardiovasc Electrophysiol 12: 1286-1294, 2001.

22. Gussak I, Chaitman BR, Kopecky SL and Nerbonne JM: Rapid ventricular repolarization in rodents: Electrocardiographic manifestations, molecular mechanisms, and clinical insights. J Electrocardiol 33: 159-170, 2000.

23. Fabritz L, Kirchhof P, Franz MR, Eckardt L, Mönnig G, Milberg P, Breithardt G and Haverkamp W: Prolonged action potential durations, increased dispersion of repolarization, and polymorphic ventricular tachycardia in a mouse model of proarrhythmia. Basic Res Cardiol 98: 25-32, 2003.

24. Wu TJ, Lin SF, Weiss JN, Ting CT and Chen PS: Two types of ventricular fibrillation in isolated rabbit hearts: Importance of excitability and action potential duration restitution. Circulation 106: 1859-1866, 2002.

25. Saumarez RC and Grace AA: Paced ventricular electrogram fractionation and sudden death in hypertrophic cardiomyopathy and other non-coronary heart diseases. Cardiovasc Res 47: 11-22, 2000

26. Papadatos GA, Wallerstein PM, Head CE, Ratcliff R, Brady PA, Benndorf K, Saumarez RC, Trezise AE, Huang CL, Vandenberg JI, et al: Slowed conduction and ventricular tachycardia after targeted disruption of the cardiac sodium channel gene Scn5a. Proc Natl Acad Sci USA 99: 6210-6215, 2002.

27. Wolk R, Kane KA, Cobbe SM and Hicks MN: Regional electrophysiological effects of hypokalaemia, hypomagnesaemia and hyponatraemia in isolated rabbit hearts in normal and ischaemic conditions. Cardiovasc Res 40: 492-501, 1998

28. Wiener N and Rosenblueth A: The mathematical formulation of the problem of conduction of impulses in a network of connected excitable elements, specifically in cardiac muscle. Arch Inst Cardiol Mex 16: 205-265, 1946.

29. Sabir IN, Li LM, Grace AA and Huang CL: Restitution analysis of alternans and its relationship to arrhythmogenicity in hypokalaemic Langendorff-perfused murine hearts. Pflugers Arch 455 653-666, 2008.

30. Mironov S, Jalife J and Tolkacheva EG: Role of conduction velocity restitution and short-term memory in the development of action potential duration alternans in isolated rabbit hearts Circulation 118: 17-25, 2008

31. Watanabe MA, Fenton FH, Evans SJ, Hastings HM and Karma A: Mechanisms for discordant alternans. J Cardiovase Electrophysiol 12: 196-206, 2001.

32. Banville I and Gray RA: Effect of action potential duration and conduction velocity restitution and their spatial dispersion on alternans and the stability of arrhythmias. J Cardiovasc Electrophysiol 13: 1141-1149, 2002.

33. NICE: Implantable cardioverter defibrillators and cardiac resynchronisation therapy for arrhythmias and heart failure. NICE technology appraisal guidance [TA314], 2014. http://www.nice. org.uk/guidance/ta314. Accessed December 21, 2015.

34. Adabag AS, Luepker RV, Roger VL and Gersh BJ: Sudden cardiac death: Epidemiology and risk factors. Nat Rev Cardiol 7: 216-225, 2010

35. Chugh SS, Reinier K, Teodorescu C, Evanado A, Kehr E, Al Samara M, Mariani R, Gunson K and Jui J: Epidemiology of sudden cardiac death: Clinical and research implications. Prog Cardiovasc Dis 51: 213-228, 2008.

36. Rastegar A and Soleimani M: Hypokalaemia and hyperkalaemia. Postgrad Med J 77: 759-764, 2001

37. Soar J, Deakin CD, Nolan JP, Abbas G, Alfonzo A, Handley AJ, Lockey D, Perkins GD and Thies K; European Resuscitation Council: European Resuscitation Council guidelines for resuscitation 2005. Section 7. Cardiac arrest in special circumstances. Resuscitation 67 (Suppl 1): S135-S170, 2005.

38. Franz MR, Burkhoff D, Spurgeon H, Weisfeldt ML and Lakatta EG In vitro validation of a new cardiac catheter technique for recording monophasic action potentials. Eur Heart J 7: 34-41, 1986

39. Hoffman BF, Cranefield PF, Lepeschkin E, Surawicz B and Herrlich HC: Comparison of cardiac monophasic action potentials recorded by intracellular and suction electrodes. Am J Physiol 196: 1297-1301, 1959.
40. Sun D, Samuelson LC, Yang T, Huang Y, Paliege A, Saunders T, Briggs J and Schnermann J: Mediation of tubuloglomerular feedback by adenosine: Evidence from mice lacking adenosine 1 receptors. Proc Natl Acad Sci USA 98: 9983-9988, 2001.

41. Osadchii OE, Larsen AP and Olesen SP: Predictive value of electrical restitution in hypokalemia-induced ventricular arrhythmogenicity. Am J Physiol Heart Circ Physiol 298: H210-H220, 2010.

42. Osadchii OE: Effects of ventricular pacing protocol on electrical restitution assessments in guinea-pig heart. Exp Physiol 97: 807-821, 2012

43. Osadchii OE: Mechanisms of hypokalemia-induced ventricular arrhythmogenicity. Fundam Clin Pharmacol 24: 547-559, 2010.

44. Brugada P and Wellens HJ: Early afterdepolarizations: Role in conduction block, 'prolonged repolarization-dependent reexcitation' and tachyarrhythmias in the human heart. Pacing Clin Electrophysiol 8: 889-896, 1985.

45. Di Diego JM and Antzelevitch C: Pinacidil-induced electrical heterogeneity and extrasystolic activity in canine ventricular tissues. Does activation of ATP-regulated potassium current promote phase 2 reentry? Circulation 88: 1177-1189, 1993.

46. January CT and Riddle JM: Early afterdepolarizations: Mechanism of induction and block. A role for L-type $\mathrm{Ca}^{2+}$ current. Circ Res 64: 977-990, 1989.

47. January CT, Riddle JM and Salata JJ: A model for early afterdepolarizations: Induction with the $\mathrm{Ca}^{2+}$ channel agonist Bay K 8644. Circ Res 62: 563-571, 1988.

48. January CT, Chau V and Makielski JC: Triggered activity in the heart: Cellular mechanisms of early after-depolarizations. Eur Heart J 12 (Suppl F): 4-9, 1991.

49. Li G, Whittaker P, Yao M, Kloner RA and Przyklenk K: The gap junction uncoupler heptanol abrogates infarct size reduction with preconditioning in mouse hearts. Cardiovasc Pathol 11: 158-165, 2002.

50. Chen BP, Mao HJ, Fan FY, Bruce IC and Xia Q: Delayed uncoupling contributes to the protective effect of heptanol against ischaemia in the rat isolated heart. Clin Exp Pharmacol Physiol 32: 655-662, 2005.

51. Sun B, Qi X and Jiang J: Heptanol decreases the incidence of ischemia-induced ventricular arrhythmias through altering electrophysiological properties and connexin 43 in rat hearts. Biomed Rep 2: 349-353, 2014.

52. Kuo CS, Munakata K, Reddy CP and Surawicz B: Characteristics and possible mechanism of ventricular arrhythmia dependent on the dispersion of action potential durations. Circulation 67: 1356-1367, 1983.

53. Shaw RM and Rudy Y: Ionic mechanisms of propagation in cardiac tissue. Roles of the sodium and L-type calcium currents during reduced excitability and decreased gap junction coupling. Circ Res 81: 727-741, 1997.

54. Rohr S: Role of gap junctions in the propagation of the cardiac action potential. Cardiovasc Res 62: 309-322, 2004.

55. Fast VG and Kléber AG: Block of impulse propagation at an abrupt tissue expansion: Evaluation of the critical strand diameter in 2- and 3-dimensional computer models. Cardiovase Res 30: 449-459, 1995.

56. Leon LJ and Roberge FA: Directional characteristics of action potential propagation in cardiac muscle. A model study. Circ Res 69: 378-395, 1991

57. Moss AJ, Schwartz PJ, Crampton RS, Tzivoni D, Locati EH, MacCluer J, Hall WJ, Weitkamp L, Vincent GM and Garson A Jr: The long QT syndrome. Prospective longitudinal study of 328 families. Circulation 84: 1136-1144, 1991.

58. Linker NJ, Colonna P, Kekwick CA, Till J, Camm AJ and Ward DE: Assessment of QT dispersion in symptomatic patients with congenital long QT syndromes. Am J Cardiol 69: 634-638, 1992.

This work is licensed under a Creative Commons

Attribution 4.0 International (CC BY 4.0) License. 